\title{
Electrocatalytic metal hydride generation using concerted proton electron transfer mediators
}

\author{
Authors: Subal Dey ${ }^{1,2}$, Fabio Masero ${ }^{1}$, Enzo Brack ${ }^{1}$, Marc Fontecave $^{2}$, Victor Mougel ${ }^{1 *}$
}

\section{Affiliations:}

${ }^{1}$ Department of Chemistry and Applied Biosciences, ETH Zürich, Zürich, Switzerland.

${ }^{2}$ Laboratoire de Chimie des Processus Biologiques, UMR 8229 CNRS, Collège de France, Sorbonne Université, Paris, France.

*Corresponding author. Email: mougel@inorg.chem.ethz.ch

Abstract: The electrochemical generation of metal hydride (M-H) species remains one of the major hurdles for a wide range of catalytic reactions to be carried out electrochemically. We introduce here a new strategy for electrocatalytic $\mathrm{M}-\mathrm{H}$ generation using concerted proton electron transfer (CPET) mediators. We investigate the combination of a series of CPET mediators with the $\mathrm{CO}_{2}$ electroreduction catalyst $\left[\mathrm{Mn}^{\mathrm{I}}(\mathrm{bpy})(\mathrm{CO})_{3} \mathrm{Br}\right]$ (bpy $=2,2$ '-bipyridine), probing the reversal of the product selectivity from $\mathrm{CO}$ to $\mathrm{HCOOH}$ to evaluate the efficiency of the M-H generation step. We demonstrate the formation of the manganese-hydride by insitu spectroscopic techniques and determine the thermodynamic boundary conditions for this mechanism to occur. A synthetic iron-sulfur cluster is identified as the best CPET-mediator for that system, enabling the preparation of a benchmark catalytic system for $\mathrm{HCOOH}$ generation.

One-Sentence Summary: An iron-sulfur cluster acts as an efficient mediator to enable electrocatalytic $\mathrm{Mn}-\mathrm{H}$ generation and subsequent transfer to $\mathrm{CO}_{2}$.

\section{Main Text:}

Transition metal hydrides (M-Hs) are ubiquitous intermediates in a wide number of catalytic reactions, ranging from biological energy conversion to industrial processes. These notably play a central role in the $\mathrm{H}^{+} / \mathrm{H}_{2}$ interconversion,(1) in the reduction of $\mathrm{CO}_{2}$ to formic acid,(2) as well as in a broad range of hydrogenation reactions. $(3,4)$ The facile generation of metal hydrides is arguably one of the most important challenges to address in order to further improve the energy efficiency of these reactions. In particular, the electrochemical generation of M-Hs constitutes one of the main hurdles to overcome to enable the sustainable conversion of small molecules $\left(\mathrm{H}_{2} \mathrm{O}, \mathrm{CO}_{2}\right.$ and $\mathrm{N}_{2}$ reduction) using renewable electricity sources.

In mechanistic terms, the electrochemical generation of a $\mathrm{M}-\mathrm{H}$ typically requires the reduction of the metal center followed by the transfer of a proton and an electron in a stepwise fashion, either via an electron transfer-proton transfer (ET-PT) or a PT-ET sequence (Fig. 1A, grey box).(5, 6) Such sequential processes involve the transfer of electrons and protons from different sources (the solid electrode and the electrolyte, respectively) which require the generation of highly reduced oxidation states of the metal center or the use of strong acids, lowering the energy efficiency and rates. Alternatively, the transfer of an electron and a proton can occur in one kinetic step, called concerted proton-electron transfer (CPET). This enables higher rates while requiring only low driving force, i.e. moderate reducing potentials and weak acids. In addition, the use of milder proton sources minimizes the chances of quenching the hydride species to generate $\mathrm{H}_{2}$, a main point to enable high selectivity when $\mathrm{H}_{2}$ is not the product targeted.

Major advances in M-H mediated electrocatalysis have recently been reported via the introduction of redox mediators to facilitate the $\operatorname{ET~} \operatorname{step}(7,8)$ or via the use of proton shuttles to smoothen the PT step. $(1,9,10)$ Relatedly, a few examples of electrocatalytic CPET 
mediators, capable of the simultaneous transfer of a proton and an electron, have been shown very successful at increasing reaction rates in both oxidative(11-13) and reductive processes. $(14,15)$ However, to the best of our knowledge, the use of a CPET mediator to mediate the electrocatalytic generation of a metal hydride has never been reported (Fig. 1A; blue box).

A Electrochemical pathways for $\mathrm{M}-\mathrm{H}$ generation

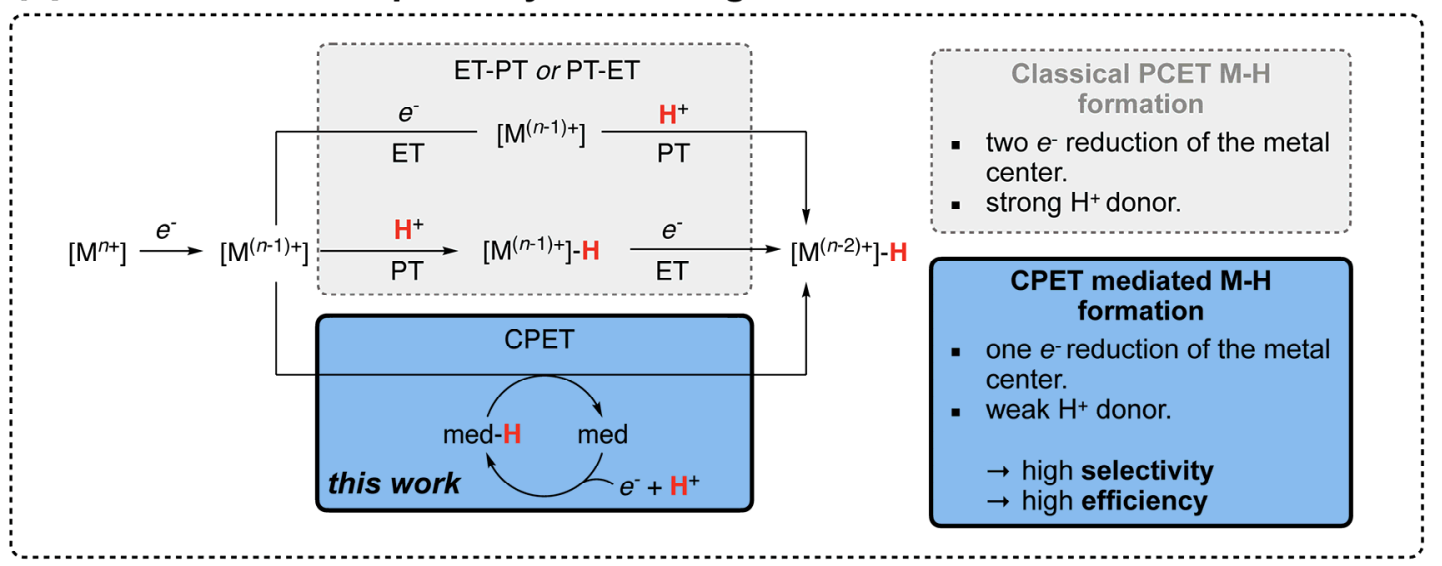

\section{$\mathrm{B} \mathrm{CO}_{2} \mathrm{RR}$ product selectivity for Mn'-cat}

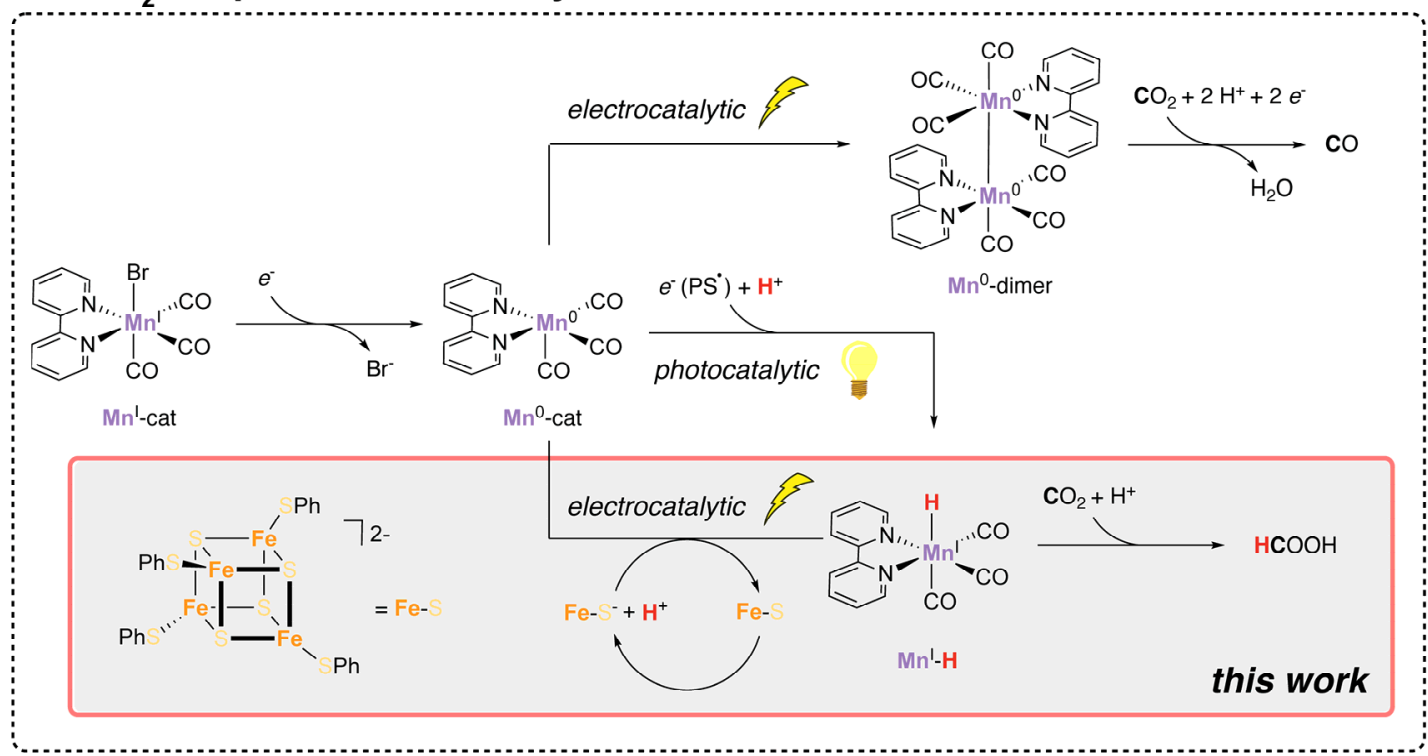

Fig. 1: CPET mediated metal hydride formation (A) Generation of M-H species via stepwise electron-proton transfer (ET-PT or PT-ET) and CPET processes. (B) Reaction pathways and associated product selectivity for $\mathrm{Mn}^{\mathrm{I}}$-cat catalyzed $\mathrm{CO}_{2}$ reduction under electro- and photochemical conditions.

Herein, we demonstrate that the use of appropriately chosen CPET mediators enables the energy efficient electrocatalytic generation of $\mathrm{M}-\mathrm{H}$ species and explore the potential of this approach for the electrocatalytic transformation of $\mathrm{CO}_{2}$ (Fig. 1B). We report that the iron-sulfur cluster $\left[\mathrm{Fe}_{4} \mathrm{~S}_{4}(\mathrm{SPh})_{4}\right]^{2-}(\mathbf{F e}-\mathrm{S})$ can be used as a CPET mediator in presence of $\left[\mathrm{Mn}^{\mathrm{I}}(\mathrm{bpy})(\mathrm{CO})_{3} \mathrm{Br}\right]\left(\mathbf{M n}^{\mathrm{I}}\right.$-cat$)$ to promote the electrocatalytic formation of a manganese hydride species. We demonstrate that this strategy allows shifting the $\mathrm{CO}_{2}$ reduction reaction $\left(\mathrm{CO}_{2} \mathrm{RR}\right)$ selectivity of $\mathbf{M n}^{\mathrm{I}}$-cat from $\mathrm{CO}$ to $\mathrm{HCOOH}$ and the identification of one of the most active catalytic systems for the selective reduction of $\mathrm{CO}_{2}$ to $\mathrm{HCOOH}$. This example enabled us to validate the boundary conditions for the choice of CPET mediators for the electrochemical generation of metal hydrides. 
The choice of an appropriate CPET mediator (med) for catalytic $\mathrm{M}-\mathrm{H}$ formation requires optimizing two CPET steps being i.) the (re)generation of the med-H species with an electron and a proton (note that med-H corresponds here to the mediator med that stores one electron and one proton, not necessarily on the same site) and ii.) the overall transfer of an apparent hydrogen atom (i.e. a proton and an electron) to the singly reduced metal site (Fig. 1A). The thermodynamic and kinetic parameters to meet for an efficient $\mathrm{M}-\mathrm{H}$ generation using a CPET mediator are ultimately fixed by the BDFE (bond dissociation free energy) and $\mathrm{p} K_{\mathrm{a}}$ values of the generated hydride species, and thus the choice of the CPET mediator used should be tailored to the $\mathrm{M}-\mathrm{H}$ species targeted and in fine to the desired catalytic application. In the present work, we investigated the impact of the proposed CPET-mediated generation of $\mathrm{M}-\mathrm{Hs}$ in the context of $\mathrm{CO}_{2}$ electroreduction, as the formation of $\mathrm{M}-\mathrm{H}$ intermediates is known to impact the catalyst's selectivity and product distribution. Molecular electrocatalysts for $\mathrm{CO}_{2} \mathrm{RR}$ are for the vast majority promoting two electron reduction of $\mathrm{CO}_{2}$ to $\mathrm{CO}$ or $\mathrm{HCOOH}$, the latter requiring an $\mathrm{M}-\mathrm{H}$ intermediate while $\mathrm{CO}$ formation typically requires the direct interaction of $\mathrm{CO}_{2}$ with the metal center and excludes $\mathrm{M}-\mathrm{H}$ formation.(2) Among the widely investigated selective $\mathrm{CO}_{2} \mathrm{RR}$ catalysts, we selected $\mathbf{M n}$-cat thanks to its divergent behavior in the electrochemical and photochemical $\mathrm{CO}_{2} \mathrm{RR}$ (Fig. 1B). It produces $\mathrm{CO}$ under electrochemical conditions(16) while generating $\mathrm{HCOOH}$ as the major product in photochemical conditions.(17) This change of selectivity relates directly to the reaction pathway involved during catalysis: the $\mathrm{C}$-centered activation of $\mathrm{CO}_{2}$ under electrochemical conditions leads to $\mathrm{CO}$ as the main product while the manganese hydride species $(\mathrm{Mn}-\mathrm{H})$ formed under photochemical conditions enables $\mathrm{HCOOH}$ formation (Fig. 1B).(18) Despite several hypotheses, the factors influencing the formation of $\mathrm{Mn}-\mathrm{H}$ species in such molecular complexes under photochemical conditions are not fully understood, and recent work highlighted that the proximity of proton donors in the ligand framework may enable the generation of $\mathrm{Mn}-\mathrm{H}$ species also under electrochemical conditions.(19, 20)

An initial screening of the thermodynamic feasibility of such a CPET-mediated Mn-H formation using reported $\operatorname{BDFE}$ values $(21,22)$, discussed in further details below in text, motivated our choice of iron-sulfur clusters (Fe-S clusters) as CPET mediators. Synthetic Fe-S clusters have so far never been used to mediate CPET steps in a catalytic context. However, proton-coupled electron transfers mediated by Fe-S clusters have been observed in Fe-Fe hydrogenases (23) (H-cluster) as well as in 3Fe-4S cluster containing ferredoxins, (24) and recent studies have shown that synthetic Fe-S clusters are also capable of donating or accepting an effective $\mathrm{H}$-atom in a stoichiometric reaction. $(21,25)$ In addition, their very low reorganization energy, which is key to the high efficiency of electron transfers in enzymatic systems, $(26,27)$ is highly desirable for an efficient (re)generation when used as a CPETmediator. Based on these facts, we investigated the $\mathrm{CO}_{2} \mathrm{RR}$ using the synthetic iron-sulfur cluster $\mathbf{F e}-\mathbf{S}$ as a potential CPET mediator in combination with the well-known $\mathrm{CO}_{2}$ reduction catalyst $\mathbf{M} \mathbf{n}^{\mathrm{I}}$-cat.

Under an Ar atmosphere, the cyclic voltammogram (CV) of a 1:1 mixture of both $\mathbf{M n}^{\mathrm{I}}$-cat and Fe-S cluster in acetonitrile $\left(\mathrm{CH}_{3} \mathrm{CN}\right)$ (see Supplementary Materials, section 2.1.1)) appears identical to the sum of the CVs of its individual components, revealing three consecutive $1 e^{-}$reduction events at $-1.34 \mathrm{~V},-1.65 \mathrm{~V}$ and $-2.05 \mathrm{~V}$ (Fig. S1; potentials expressed $v s . \mathrm{Fc} / \mathrm{Fc}^{+}$here and in all text below). These events were respectively assigned to the $\mathbf{F e}-\mathbf{S}^{0 /-1}$ redox process and to the reduction of $\mathbf{M n} \mathbf{n}^{\mathbf{I}}$-cat to the dimeric complex $\left[\mathrm{Mn}^{0} \text { (bpy) }(\mathrm{CO})_{3}\right]_{2}\left(\mathbf{M n}^{\mathbf{0}}\right.$-dimer) first and the subsequent reduction of the dimer to the $\mathbf{M n}^{-1}$-cat species (Fig. 1B; see Supplementary Materials, section 2.1.1 for details). 

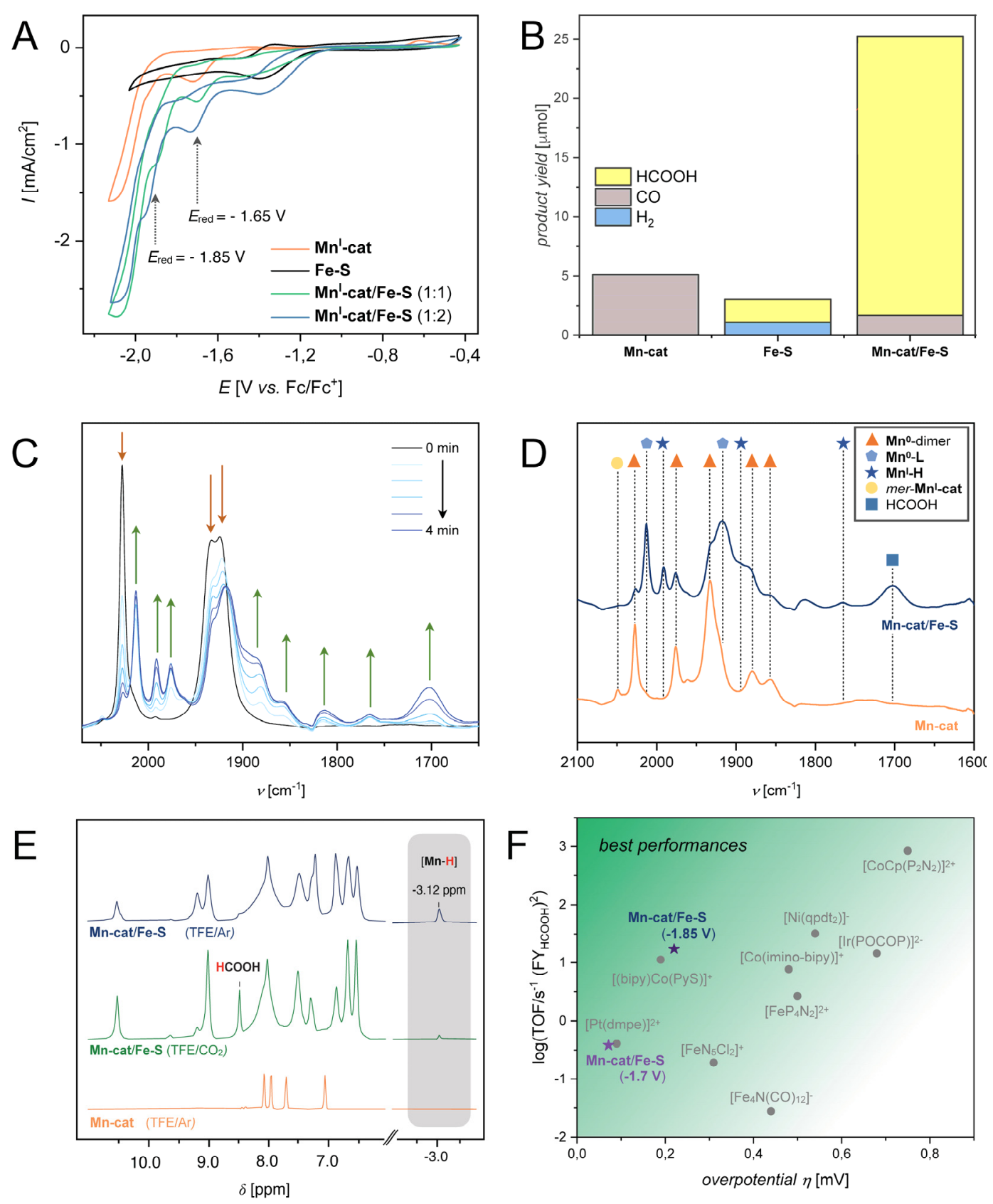

Fig. 2: Catalytic activity and spectroscopic characterization of relevant intermediates of CPET mediated $\mathrm{CO}_{2} \mathbf{R R}$ activity of $\mathrm{Mn}^{\mathrm{I}}$-cat. (A) Overlaid CV data of $\mathbf{M n}^{\mathrm{I}}$-cat $(1 \mathrm{mM})$ in the absence or in the presence of $\mathbf{F e}-\mathbf{S}$ along with the $\mathrm{CV}$ of $\mathbf{F e}-\mathbf{S}$ alone in the presence of $\mathrm{CO}_{2}\left(0.2 \mathrm{M}\right.$ TFE, $0.1 \mathrm{M} \mathrm{TBAPF}_{6}$ in $\mathrm{CO}_{2}$-saturated $\left.\mathrm{CH}_{3} \mathrm{CN}\right)$. (B) Corresponding products obtained during $90 \mathrm{~min}$ CPE at $-1.85 \mathrm{~V}$ using a 1:2 $\mathbf{M n}^{\mathbf{I}}$-cat/Fe-S mixture under identical conditions (0.2 M TFE, 0.1 M TBAPF 6 in $\mathrm{CO}_{2}$-saturated $\left.\mathrm{CH}_{3} \mathrm{CN}\right)$. (C) Time dependent evolution of IRSEC signals of a 1:2 $\mathbf{M n}^{\mathrm{I}}$-cat/Fe-S mixture in the presence of $\mathrm{CO}_{2}$ upon reduction at $-1.65 \mathrm{~V}$ (40 equiv. TFE, $0.1 \mathrm{M}$ TBAPF 6 in $\mathrm{CO}_{2}$-saturated $\mathrm{CH}_{3} \mathrm{CN}$ ). (D) Overlay of the IRSEC signals after 4 min CPE of a 1:2 $\mathbf{M n}^{\mathrm{I}}$-cat/Fe-S mixture (blue) and $\mathbf{M n}^{\mathrm{I}}$-cat only (red) under the conditions described in C. (E) Ex-situ ${ }^{1} \mathrm{H}-\mathrm{NMR}$ spectra of Mn $\mathbf{M n}^{\mathrm{I}}$-cat (orange) and a 1:1 $\mathbf{M n}^{\mathrm{I}}$-cat/Fe-S mixture recorded after CPE at $-1.65 \mathrm{~V}$ and addition of 50 equiv. of TFE under $\mathrm{Ar}$ (blue), and $\mathrm{CO}_{2}$ (green) . (F) Comparison of the performance among reported catalytic $\mathrm{CO}_{2} \mathrm{RR}$ systems selective for formic acid production (see Table $\mathrm{S} 2$ and section 2.8 of the Supplementary Materials for details). 
This behavior is markedly different under $\mathrm{CO}_{2} \mathrm{RR}$ conditions $\left(\mathrm{CO}_{2}\right.$-saturated electrolyte solution containing 0.2 M 2,2,2-trifluoroethanol (TFE) as the proton donor, see

Supplementary Materials, section 2.1.1 for detailed discussion on the choice of experimental conditions and Fig. S1-S6). The CV of the 1:1 mixture of $\mathbf{M n}^{\mathbf{I}}$-cat and Fe-S presented in Fig. 2A exhibits two significant changes with respect to the CVs of each complex taken separately: the catalytic current of the peak assigned to the electrochemical $\mathrm{CO}_{2} \mathrm{RR}$ activity of $\mathrm{Mn}^{\mathrm{I}}$-cat at $-2.05 \mathrm{~V}$ is enhanced by ca. $50 \%$ and a new catalytic feature appears at $-1.85 \mathrm{~V}$ (note that Fe-S alone does not show any catalytic features within the experimental potential range). In addition, a small current enhancement ( 2.4 times) of the peak at $-1.65 \mathrm{~V}$ is observed under $\mathrm{CO}_{2} \mathrm{RR}$ conditions. In the absence of $\mathrm{CO}_{2}$ or TFE, the catalytic process at $-2.05 \mathrm{~V}$ is not present and the process at $-1.85 \mathrm{~V}$ is substantially lowered, while the $\mathbf{F e - \mathbf { S } ^ { 0 / - 1 }}$ process remained unaltered (Fig. S2 and S3). Increasing the concentration of Fe-S (1:2 $\mathbf{M n}$-cat/Fe-S ratio) does not impact the current of the $-2.05 \mathrm{~V}$ peak but results in a further increase of the catalytic current at $-1.85 \mathrm{~V}$ (Fig. 2A). These results suggest that the new catalytic process at $-1.85 \mathrm{~V}$ is related to the generation of a new catalytic species resulting from the synergistic combination of $\mathbf{F e}-\mathbf{S}$ and $\mathbf{M n}{ }^{\mathbf{I}}$-cat and occurring at less negative potentials than that required for $\mathbf{M n}$-cat alone to reduce $\mathrm{CO}_{2}$. To identify the reaction catalyzed at this new catalytic process, we carried out a series of 90 min controlled potential electrolyses (CPEs) (Fig. S7). A CPE at-1.85 V revealed a complete shift of product selectivity and formation rates (Fig. 2B): the 1:2 combination of $\mathbf{M n} \mathbf{I}^{\mathbf{I}}$-cat and $\mathbf{F e}-\mathbf{S}$ enabled the formation of a large amount of $\mathrm{HCOOH}$ with high selectivity $\left(\mathrm{FY} \mathrm{HCOOH} 92 \%, n_{\mathrm{HCOOH}}=\right.$ $23 \mu \mathrm{mol})$ and a small amount of $\mathrm{CO}\left(\mathrm{FY}_{\mathrm{CO}} 6 \%, n_{\mathrm{CO}}=1.6 \mu \mathrm{mol}\right)$, while $\mathbf{M n}^{\mathrm{I}}$-cat alone catalyzes $\mathrm{CO}_{2} \mathrm{RR}$ selectively, as expected, to $\mathrm{CO}$ with low activity $\left(\mathrm{FY}_{\mathrm{CO}} 91 \%, n_{\mathrm{CO}}=\right.$ $5 \mu \mathrm{mol}$ ) with no formation of $\mathrm{H}_{2}$ and $\mathbf{F e}-\mathbf{S}$ alone only produces a very small amount of $\mathrm{HCOOH}\left(\mathrm{FY}_{\mathrm{HCOOH}} 30 \%, \mathrm{nHCOOH}=1.9 \mu \mathrm{mol}\right)$ and $\mathrm{H}_{2}\left(\mathrm{FY}_{\mathrm{H}_{2}} 17 \%, n_{\mathrm{H}_{2}}=1 \mu \mathrm{mol}\right)$ (Table S1). We identified the 1:2 $\mathbf{M n}{ }^{\mathbf{I}}$-cat/Fe-S ratio as optimal, since both the amount of products formed and the selectivity for $\mathrm{HCOOH} v s$. $\mathrm{CO}$ were enhanced when increasing the concentration of $\mathbf{F e}-\mathbf{S}$ (i.e. decreasing the $\mathbf{M} \mathbf{n}^{\mathrm{I}}$-cat/Fe-S ratio), reaching a plateau at a 1:2 ratio (Fig. S7 and Table S1). Most importantly, with an overall turnover frequency (TOF) of $20 \mathrm{~s}^{-1}$ at an overpotential of only $220 \mathrm{mV}$ measured from the long-term CPE experiment, the 1:2 Mn-Cat/Fe-S system stands among the best molecular electrocatalytic systems for the reduction of $\mathrm{CO}_{2}$ to $\mathrm{HCOOH}$, while operating at remarkably high faradaic efficiency (see section 2.8 in Supplementary Materials and Fig. 2F). In addition, independently of the selectivity shift, a ca. sixfold increase in turnover number (TON) for $\mathrm{CO}_{2} \mathrm{RR}$ was observed with respect to the analogous CPE carried out in the absence of Fe-S (Table S1).

Finally, the origin of the above-mentioned increase of the current at $-1.65 \mathrm{~V}$ under catalytic conditions with the 1:2 Mn-Cat/Fe-S system was investigated by carrying out a CPE at $-1.7 \mathrm{~V}$. Highly selective $\mathrm{HCOOH}$ formation was also observed $\left(\mathrm{FY}_{\mathrm{HCOOH}} 91 \%, n_{\mathrm{HCOOH}}=\right.$ $9.5 \mu \mathrm{mol}$, Table S1) yet with significantly lower rates (TOF $\left.=0.46 \mathrm{~s}^{-1}\right)$ than observed at $-1.85 \mathrm{~V}$. Nevertheless, selective reduction of $\mathrm{CO}_{2}$ to formic acid at such a modest overpotential $(70 \mathrm{mV})$ is to our knowledge unprecedented for $1^{\text {st }}$ row transition metal catalysts (Fig. 2F).

Last, $\mathrm{CPE}$ at the third catalytic wave $\left(E_{\text {red }}=-2.05 \mathrm{~V}\right)$ with a 1:2 ratio of $\mathbf{M n}$-Cat $/ \mathbf{F e}-\mathbf{S}$ revealed an increased $\mathrm{CO}: \mathrm{HCOOH}$ ratio $\left(\mathrm{FY}_{\mathrm{CO}} 32 \%, \mathrm{FY}_{\mathrm{HCOOH}} 56 \%\right)$ together with small amounts of $\mathrm{H}_{2}\left(\mathrm{FY}_{\mathrm{H}_{2}} 6 \%\right)$. This lowered selectivity for formate is consistent with the combination of the catalytic process at $-1.85 \mathrm{~V}$ mentioned above and the catalytic process at $-2.05 \mathrm{~V}$ originating from the residual activity of $\mathbf{M n}^{\mathrm{I}}$-Cat, as suggested by the CV studies. Decomposition of the complexes under catalytic conditions and modulation of the reactivity by potential side-products of the solvolysis of Fe-S were ruled out (see Supplementary Materials, section 2.9 and Fig. S9 - S10 for detailed discussion). 
Such a change of selectivity from $\mathrm{CO}$ to $\mathrm{HCOOH}$ suggests the formation of a $\mathrm{Mn}-\mathrm{H}$ intermediate $(19,20)$ in the presence of $\mathbf{F e - S}$ and prompted us to investigate reaction intermediates via in-situ spectroscopic techniques. In-situ infrared spectroscopy (IRSEC) studies under optimized catalytic conditions $\left(\mathrm{CO}_{2}\right.$-saturated electrolyte solution, 40 equiv. TFE, $2 \mathrm{mM} \mathrm{Mn} \mathbf{M n}^{\mathrm{I}}$-cat and $4 \mathrm{mM}$ Fe-S), revealed the appearance of the characteristic $v_{\mathrm{CO}}$ vibrations of the $\mathrm{Mn}(\mathrm{I})$-hydride complex $\left[\mathrm{Mn}^{\mathrm{I}}(\mathrm{bpy})(\mathrm{CO})_{3} \mathrm{H}\right](\mathbf{M n} \mathbf{I}-\mathbf{H})$ at 1990 and $1892 \mathrm{~cm}^{-1}$ together with a weak vibration at $1764 \mathrm{~cm}^{-1}$ when the potential of the cell was held below ca. -1.65 V. While the carbonyl stretches $v_{\mathrm{CO}}$ of the $\mathbf{M n}^{\mathrm{I}}-\mathbf{H}$ have been reported (Fig. 2C and Fig S11), $(19,28)$ the new $1764 \mathrm{~cm}^{-1}$ band observed here lies in the range of reported $\mathrm{Mn}-\mathrm{H}$ vibrations(29) and can be tentatively assigned to the corresponding $v \mathrm{Mn}-\mathrm{H}$ stretch of $\mathbf{M n} \mathbf{L}-\mathbf{H}$. None of the vibrations associated to $\mathbf{M n}^{\mathbf{I}}-\mathbf{H}$ are observed in the absence of Fe-S or TFE (Fig. S12). With respect to the IRSEC spectrum recorded in the absence of Fe-S (Fig. 2D orange line), a striking feature of the IRSEC spectrum of the 1:2 Mn-Cat/Fe-S system (Fig. 2D blue line) is the relatively lower intensity of the $v_{\mathrm{CO}}$ vibrations at $1975,1934,1878$ and $1853 \mathrm{~cm}^{-1}$ assigned to $\mathbf{M n}^{\mathbf{0}}$-dimer (see Fig. 2D, Table S4 and section 3.1 of Supplementary Materials). This suggests that the promoted formation of $\mathbf{M n}^{\mathrm{I}}-\mathbf{H}$ in presence of $\mathbf{F e}-\mathbf{S}$ hinders the dimerization of the $\mathrm{Mn}(0)$ complex $\left[\mathrm{Mn}^{0}(\mathrm{bpy})(\mathrm{CO})_{3}\right]\left(\mathbf{M n}^{\mathbf{0}}\right.$-cat) to $\mathbf{M n}^{\mathbf{0}}$-dimer. In addition, the appearance of a set of $v_{\text {CO }}$ vibrations at 2012, 1935(sh) and $1920 \mathrm{~cm}^{-1}$ points to the formation of a neutral $\left[\mathrm{Mn}(\mathrm{bpy})(\mathrm{CO})_{3} \mathrm{~L}\right]\left(\mathbf{M n}^{\mathbf{0}}-\mathbf{L}\right)$ complex $(28)(\mathbf{L}$ being a neutral ligand such as $\mathrm{CH}_{3} \mathrm{CN}$, Fig. 2D and Fig. S12). Such a complex is not observed in the absence of Fe-S and we tentatively attribute its formation to a weak interaction between the reduced cluster $\left[\mathrm{Fe}_{4} \mathrm{~S}_{4}(\mathrm{SPh})_{4}\right]^{3-}\left(\mathbf{F e}-\mathrm{S}^{-\mathbf{1}}\right)$ and $\mathbf{M n}^{\mathbf{I}}$-cat that triggers $\mathrm{Br}^{-}$release and the subsequent reduction of the cationic acetonitrile complex. In-situ formation of $\mathrm{HCOOH}$ was further confirmed by the appearance of its characteristic vibration at $1700 \mathrm{~cm}^{-1}$.(19) When the potential of the IRSEC cell is shifted slightly further negative (approximatively $-1.85 \mathrm{~V}$ ), we observed a decay of the vibrations associated to $\mathbf{M n} \mathbf{I}-\mathbf{H}$ along with the growth of at the vibration $1700 \mathrm{~cm}^{-1}$ suggesting intense formic acid generation (Fig. S14). The additional vibrations at 1911 and $1810 \mathrm{~cm}^{-1}$, which further grow when the potential of the cell is shifted to more negative values are attributed to $\left[\mathrm{Mn}(\mathrm{bpy})(\mathrm{CO})_{3}\right]^{-}\left(\mathbf{M n}^{-1}\right.$-cat $) .(30) \mathbf{M n}^{-1}$-cat catalyzes the selective reduction of $\mathrm{CO}_{2}$ to $\mathrm{CO}$ and its gradual appearance at the most negative potentials is consistent with the increased FYs for $\mathrm{CO}$ observed in $\mathrm{CPE}$ experiments at potentials below $-1.85 \mathrm{~V}$.

Formation of $\mathbf{M n}^{\mathrm{I}}-\mathbf{H}$ was further confirmed by the appearance of a hydride resonance at $-3.12 \mathrm{ppm}$ in the ${ }^{1} \mathrm{H}$ NMR of a 1:1 solution of Mn-Cat/Fe-S, reduced by a CPE step at $-1.65 \mathrm{~V}$ in $\mathrm{CD}_{3} \mathrm{CN}$ followed by the addition of a $\mathrm{CO}_{2}$ saturated $T F E / \mathrm{CD}_{3} \mathrm{CN}$ solution $(2 \mathrm{M}$, $30 \mu \mathrm{L}$ ) to the NMR tube (Fig. 2E, green spectrum). The simultaneous appearance of a $\mathrm{HCOOH}$ peak $(\delta=8.4 \mathrm{ppm})$ in the ${ }^{1} \mathrm{H}$ NMR spectrum confirms the catalytic activity of the complex at that potential and explains the low intensity of the $\mathbf{M n} \mathbf{n}^{\mathbf{I}}-\mathbf{H}$ signal, as it is consumed to generate $\mathrm{HCOOH}$. Consequently, the appearance of the hydride resonance is even more pronounced when the same experiment is carried out in the absence of $\mathrm{CO}_{2}$ (Fig. 2E, blue spectrum. None of the signals associated with $\mathbf{M n}^{\mathbf{I}}-\mathbf{H}$ were observed in the absence of Fe-S under identical condition (Fig. 2E, yellow spectrum, the ${ }^{1} \mathrm{H}$ NMR confirming instead the formation of $\mathbf{M n}^{\mathbf{0}}$-dimer observed in IRSEC experiments (See section 4 of the Supplementary Materials for details).

Taken together with the CV data presented above, the IRSEC and ${ }^{1} \mathrm{H}$ NMR data provide evidence for the formation of $\mathbf{M n} \mathbf{n}^{\mathbf{I}}-\mathbf{H}$. Mn $\mathbf{M n}^{\mathbf{I}}-\mathbf{H}$ generation is observed after the $1 e^{-}$reduction of $\mathbf{M n}^{\mathbf{I}}$-cat to $\mathbf{M n}^{\mathbf{0}}$-cat, which occurs at a potential where $\mathbf{F e}-\mathbf{S}$ is already in the reduced $\mathbf{F e}-\mathbf{S}^{\mathbf{1}}$ form. Nonetheless, the absence of any IR features for $\mathbf{M n}^{\mathbf{- 1}}$-cat at this potential when no proton source was added (Fig. S12) rules out the possibility of an ET-PT mechanism mediated by $\mathbf{F e}-\mathbf{S}$ and generating $\mathbf{M n} \mathbf{I}-\mathbf{H}$ upon protonation of $\mathbf{M n}^{-1}$-cat. Relatedly, the 
quantitative dimerization of $\mathbf{M n}^{\mathbf{0}}$-cat observed in the absence of $\mathbf{F e}-\mathbf{S}$ at the potentials required for $\mathbf{M n}^{\mathbf{I}}-\mathbf{H}$ formation (Fig. S12), excludes a PT-ET mechanism. This is consistent with a CPET from an in situ generated [Fe-S]H species to $\mathbf{M n}^{\mathbf{0}}$-cat to generate $\mathbf{M} \mathbf{n}^{\mathbf{I}}-\mathbf{H}$. It highlights that the ability of iron-sulfur clusters to promote CPET, known for stoichiometric reactions, (21) can be exploited in a catalytic pathway. Most importantly, Fe-S acts as a CPET mediator for the catalytic generation of a manganese hydride species.

This prompted us to attempt determining the thermodynamic and kinetic feasibility of such a CPET-mediated metal hydride generation. As mentioned above, two CPET steps have to be considered, being i.) the (re)generation of the med-H species with an electron and a proton and ii.) the overall transfer of an apparent hydrogen atom to the singly reduced metal site $\left[\mathrm{M}^{(\mathrm{n}-1)^{+}}\right]$(Fig. 3A). Both steps can be interpreted in a Marcus-type formalism where the proton and electron is treated quantum mechanically and tunnel to the product state through the same transition state while the solvent and other reactants are treated classically. By analogy with the Marcus expression of a single charge transfer, the free-energy barrier and Arrhenius rate constant for a weakly coupled non-adiabatic CPET can be expressed according to the following expression:(31)

$$
\begin{gathered}
\Delta G^{\ddagger}{ }_{\mathrm{CPET}}=\frac{\left(\Delta G^{\circ}{ }_{C P E T}+\lambda\right)^{2}}{4 \lambda} \\
k_{\mathrm{CPET}}=A e^{\left(\frac{-\Delta G^{\ddagger} \mathrm{CPET}}{k_{\mathrm{B}} T}\right)}=A e^{\left(\frac{-\left(\Delta G^{\circ} \mathrm{CPET}+\lambda\right)^{2}}{4 \lambda k_{\mathrm{B}} T}\right)}
\end{gathered}
$$

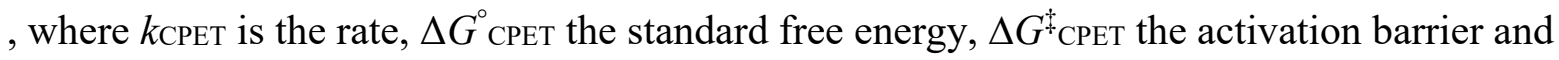
$\lambda$ the reorganization energy of the CPET process. $A$ is the pre-exponential factor that is determined from the overlap integrals of the electronic states and proton vibrational states between the substrate and product. $T$ is the absolute temperature and $k_{\mathrm{B}}$ is the Boltzmann constant.

In such an approach, a symmetric dependence between the rate of the reaction $\left(k_{\mathrm{CPET}}\right)$ and the thermodynamic driving force $\left(\Delta G_{\mathrm{CPET}}^{\circ}\right)$ is expected, resulting in a lower activation barrier than required for the stepwise ET-PT and PT-ET processes. This dependence may be diminished by the fact that both a proton and an electron must synchronously tunnel, resulting in a potentially higher pre-exponential factor $(A)$ than for isolated ET and PT steps. Nevertheless, the use of mild reducing agents and weak acid sources should mitigate that fact and enable faster CPET rates, while being highly beneficial for catalytic purposes since proceeding at a lower overall driving force $\Delta G^{\circ}$ СРET. Hence, considering the two steps of a catalytic CPET generation of a M-H species in the Marcus formalism as presented in Fig. 3 allows identifying boundary conditions for an effective catalytic $\mathrm{M}-\mathrm{H}$ formation, occurring at high rate and minimal thermodynamic cost.

First, the efficient (re)generation of the CPET mediator requires to minimize the driving force $\Delta G_{1}^{\circ}$ and the reorganization energy $\lambda_{1}$ for the generation step med $\rightarrow$ med-H. $\Delta G_{1}^{\circ}$ corresponds to the BDFE of the med-H species, and can be estimated using the Bordwell equation (3):

$$
\mathrm{BDFE}=1.346 \times \mathrm{p} K_{\mathrm{a}}+23.06 \times E^{0}+C_{\mathrm{G}}
$$

, using as $E^{0}$ the reduction potential of the $m e d^{0 /-}$ couple and as $\mathrm{p} K_{\mathrm{a}}$ the value for $m e d-\mathrm{H}$ The two main parameters impacting the reorganization energy $\lambda_{1}$ are the solvent reorganization energy and the inner-sphere reorganization energy of the mediator, related to the intrinsic geometry change that occurs upon generation of the med-H species. In the specific case of a CPET mechanism, the overall charge will not vary, and the main contributor to the overall reorganization energy will be the inner-sphere ones. A good strategy to lower $\lambda_{1}$ is hence to select a mediator with minimal structural and polarity changes upon CPET. 
Second, from a thermodynamic point of view, for the CPET transfer to occur from med-H to the reduced metal complex M (i.e. $\Delta G_{2}^{\circ}<0$ ), the BDFE of the med-H species (BDFE ${ }^{\text {med }}$-H ) should be lower than the BDFE of the corresponding M-H species (BDFE ${ }^{\mathrm{M}-\mathrm{H}}$ ) formed.(32) These values should yet be close to lower the associated kinetic energy barrier, as highlighted above.

Last, to ensure an efficient proton transfer from the proton source to the mediator, a proton source fulfilling the relation $\mathrm{p} K_{\mathrm{a}}$ proton source $\leq \mathrm{p} K_{\mathrm{a}}{ }^{\text {med }-\mathrm{H}}$ should be selected. Additional selection factors come into play when $\mathrm{H}_{2}$ generation is not the reaction of interest and will be discussed below in the text.

A Overall reaction and free energies for CPET mediated $\mathrm{M}-\mathrm{H}$ formation

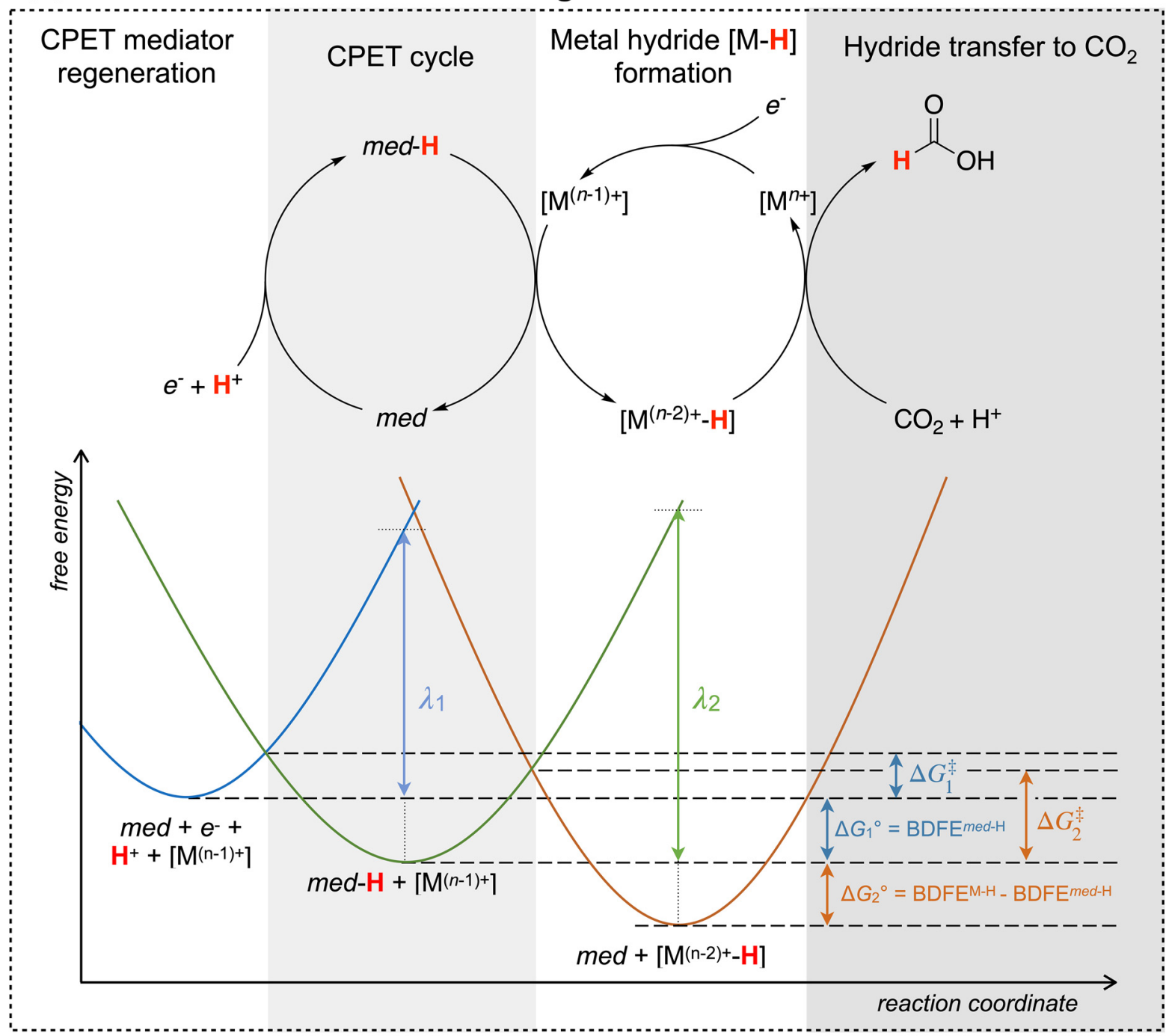

B Boundary conditions for CPET mediated M-H formation

- BDFEM-H > BDFEmed-H

- $\mathrm{p} K_{\mathrm{a}} \mathrm{H}^{+-}$donor $<\mathrm{p} K_{\mathrm{a}}$ med-H

Fig. 3: Thermodynamic and kinetic considerations for catalytic CPET mediated metal hydride formation. (A) Schematic representation of the reaction steps in a CPET mediated $\mathrm{M}-\mathrm{H}$ generation followed by hydride transfer to $\mathrm{CO}_{2}$ and the associated free-energy parabola representation. (B) Boundary conditions to be met to ensure catalytic CPET-mediated M-H generation. 
Hence, for the present system, an effective CPET can occur if the BDFE ${ }^{[\mathrm{Fe}-\mathrm{S}] \mathrm{H}}$ is lower than that of BDFE ${ }^{\mathrm{Mn}-\mathrm{H}}$. However, verifying this condition first implies determining these BDFEs that were not previously reported. We determined $\mathrm{BDFE}^{[\mathrm{Fe}-\mathrm{S}] \mathrm{H}}$ here as low as $63.5 \mathrm{kcal} / \mathrm{mol}$ using the Bordwell equation (3), in good agreement with the BDFE value of $60.5 \mathrm{kcal} / \mathrm{mol}$ (approx.) recently reported for another Fe-S cluster bearing substituted thioaryloxide ligands.(21) The determination of this value necessitated evaluating the $\mathrm{p} K_{\mathrm{a}}$ value of [Fe-S]H, which we determined electrochemically using a protonated P1 phosphazene base (see in Supplementary Materials, section 5) and found a value of $30.3 \pm 0.3$. This value lies in the expected range for this species assuming that a one electron transfer increases the $\mathrm{p} K_{\mathrm{a}}$ by 4-6 units compared to the oxidized species as observed for synthetic $\mathrm{Fe}_{2} \mathrm{~S}_{2}$ clusters. (25) The lower limit of BDFE ${ }^{\mathrm{Mn}-\mathrm{H}}$ was estimated to $65.8 \mathrm{kcal} / \mathrm{mol}$ on the basis of $\mathrm{CV}$ and ${ }^{1} \mathrm{H}$ NMR data (see in the Supplementary Materials, section 6). This value is slightly higher than those reported for other manganese hydride complexes such as $\mathrm{HMn}(\mathrm{CO})_{5}(60 \mathrm{kcal} / \mathrm{mol})$ and $\mathrm{HMn}(\mathrm{CO})_{4} \mathrm{PPh}_{3}(61 \mathrm{kcal} / \mathrm{mol})$.(22) In order to further assess and confirm the lower limit of the BDFE value for $\mathbf{M n}^{\mathrm{I}}-\mathbf{H}$, we studied the $\mathrm{CO}_{2}$ electroreduction activity and respective product ratio between $\mathrm{CO}$ and $\mathrm{HCOOH}$ of $\mathbf{M n}^{\mathrm{I}}$-cat in the presence of a series of CPET mediators (Fig. 4A) covering a range of BDFE values around this estimated lower boundary. This strategy enables the indirect evaluation of $\mathrm{BDFE}^{\mathrm{Mn}-\mathrm{H}}$ : The presence of significant amounts of $\mathrm{HCOOH}$ as a reaction product reveals the formation of $\mathbf{M n}^{\mathbf{I}}-\mathbf{H}$, and indicates that the $\mathrm{BDFE}^{\mathrm{Mn}-\mathrm{H}}$ is lower than the BDFE of the mediator to provide the upper boundary value for BDFE ${ }^{\mathrm{Mn}-\mathrm{H}}$, while its absence indicates that $\mathbf{M n} \mathbf{I}-\mathbf{H}$ is not generated and provides a lower boundary value for BDFE ${ }^{\mathrm{Mn}-\mathrm{H}}$. As $\mathbf{M n}^{\mathbf{I}}-\mathbf{H}$ is formed in the presence of $\mathbf{F e - S}$, we focused our study on CPET mediators that are reported to have BDFE values close to or larger than $\mathrm{BDFE}^{[\mathrm{Fe}-\mathrm{S}] \mathrm{H}}$ mentioned above. Fig. 4B reveals that the amount of $\mathrm{HCOOH}$ is lowered with increasing the BDFE ${ }^{m e d-H}$ of the CPET mediator using $\left[\mathrm{Ru}^{\mathrm{II}}(\mathrm{acac})_{2}(\mathrm{PyImz})\right](\mathbf{R u}-\mathbf{N H})(\mathrm{acac}=$ acetylacetonate, PyImz = 2-pyridyl-imidazole) and 2,5-di-tert-butylhydroquinone $\left(\mathbf{D T H}_{\mathbf{2}} \mathbf{Q}\right)$ and finally vanished in the presence of 1,4-dihydroquinone $\left(\mathbf{H}_{2} \mathbf{Q}\right)$ or phenol $(\mathbf{P h O H})$ where $\mathrm{CO}$ was observed to be the sole $\mathrm{CO}_{2} \mathrm{RR}$ product (see Supplementary Materials, section 7 for details). The reported BDFE values of this series of CPET donors allow concluding that the generation of $\mathbf{M n}^{\mathrm{I}}-\mathbf{H}$ occurs in presence of CPET donors with $\mathrm{BDFE}^{\text {med }-\mathrm{H}}$ below $63.5 \mathrm{kcal} / \mathrm{mol}$ but not in presence of CPET donors with $\mathrm{BDFE}^{m e d-\mathrm{H}}$ higher than $67.3 \mathrm{kcal} / \mathrm{mol}$. This suggests that BDFE ${ }^{\mathrm{Mn}-\mathrm{H}}$ for $\mathbf{M n}^{\mathrm{I}}-\mathbf{H}$ lies in between these two values, in good agreement with the experimentally determined lower boundary of $65.8 \mathrm{kcal} / \mathrm{mol}$. This first evaluation of the BDFE ${ }^{\mathrm{Mn}-\mathrm{H}}$ of $\mathbf{M n}^{\mathbf{I}}-\mathbf{H}$ allows determining the thermodynamic feasibility of the hydride transfer from $\mathbf{M n} \mathbf{I}-\mathbf{H}$ to $\mathrm{CO}_{2}$ from a hydricity point of view. $(33,34)$ The lower limit of hydricity of the $\mathbf{M n} \mathbf{I}-\mathbf{H}$ is estimated to ca. $54.4 \mathrm{kcal} / \mathrm{mol}$ according to the standard reduction potential correlation (see Supplementary Materials, section 8). This is significantly higher than the thermodynamic threshold for $\mathrm{HCOOH}$ production $(44 \mathrm{kcal} / \mathrm{mol}),(34)$ in agreement with the sluggish $\mathrm{HCOOH}$ generation mentioned above when $\mathrm{CPE}$ is carried out at $-1.7 \mathrm{~V}$ and confirms that $\mathbf{M n}^{\mathrm{I}}-\mathbf{H}$ needs to be further reduced to generate the more active catalyst. This reduction occurs at ca. $-1.85 \mathrm{~V}$ to generate a formal $\mathbf{M n}^{\mathbf{0}}-\mathbf{H}$ species, whose BDFE value can be approximated ca. 10-15 kcal/mol lower than that of $\mathbf{M n}^{\mathbf{I}}-\mathbf{H} .(35,36)$ The hydricity value of $\mathbf{M n}^{\mathbf{0}}-\mathbf{H}$ is hence fully consistent with the observed high selectivity and faster rate for $\mathrm{HCOOH}$ production. This later finding permits to validate the reaction pathway for the fast electrocatalytic $\mathrm{CO}_{2} \mathrm{RR}$ to formic acid by the composite system $\left(\mathbf{M n}^{\mathrm{I}}\right.$-cat/Fe-S) shown in Fig. 4D: Fe-S mediates a CPET step to electrogenerated $\mathbf{M n}^{\mathbf{0}}$-cat affording $\mathbf{M n}^{\mathbf{I}}-\mathbf{H}$ while hindering the competitive dimerization of $\mathbf{M n}^{\mathbf{0}}$-cat; $\mathbf{M n}^{\mathrm{I}}-\mathbf{H}$ is further reduced to generate $\mathbf{M n}^{0}-\mathbf{H}$ that subsequently mediates a hydride transfer to $\mathrm{CO}_{2}$ to generate formic acid. 

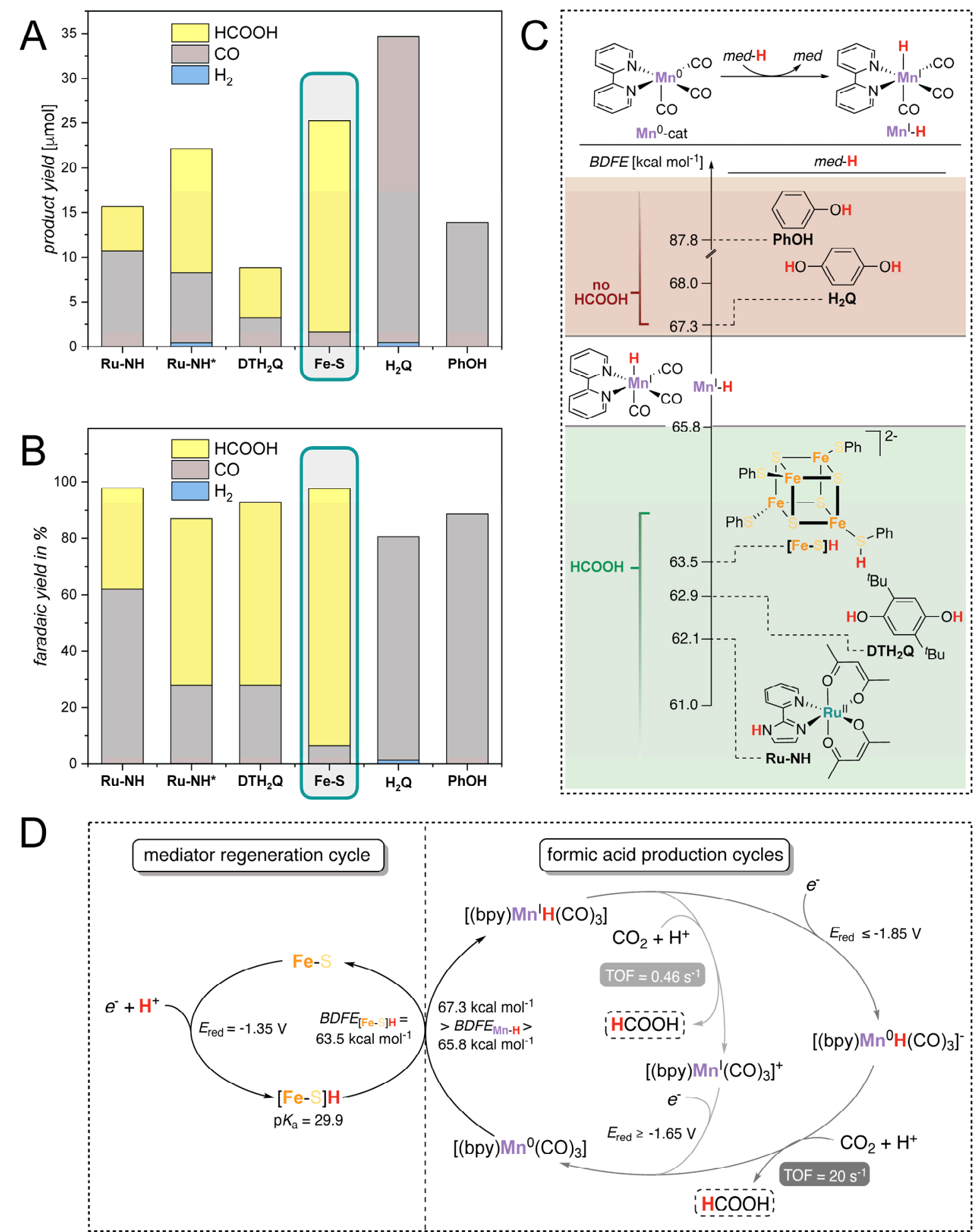

Fig. 4: $\mathrm{CO}_{2} \mathrm{RR}$ activity of $\mathrm{Mn}^{\mathrm{I}}$-cat in presence of various CPET mediators: (A) Product yields and (B) associated faradaic efficiencies for $\mathrm{CO}_{2} \mathrm{RR}$ using $\mathbf{M n}^{\mathrm{I}}$-cat in presence of various CPET mediators. The first three entries from the left correspond to experiments carried out in presence of proton source (0.2 M TFE except for Ru-NH* where $1.5 \mathrm{M} \mathrm{H}_{2} \mathrm{O}$ was used) while the other entries relate to catalytic tests carried out in the absence of proton source and at high concentration of the CPET mediator (0.1-0.5 M). (C) Scaling relation of $\mathrm{BDFE}^{\text {med-H}}$ with formic acid production, that lead to the determination of $\mathrm{BDFE}^{\mathrm{Mn}-\mathrm{H}}$ via the reaction shown on top. The BDFE values mentioned here are summarized in section 6 of 
Supplementary Materials. (D) Proposed mechanistic cycle for Fe-S mediated $\mathbf{M n} \mathbf{I}-\mathbf{H}$ formation and subsequent transfer of the hydride to $\mathrm{CO}_{2}$.

The determined BDFE and hydricity values also provide an insight on the observed reverse selectivity towards formic acid generation when $\mathbf{M n}^{\mathrm{I}}$-cat is used for photochemical $\mathrm{CO}_{2} \mathrm{RR}$. The typical observed decrease of the BDFE for the composite system made of the photosensitizer and the proton source to values below $40 \mathrm{kcal} / \mathrm{mol}$ upon light excitation(37) is sufficient to trigger the formation of $\mathbf{M} \mathbf{n}^{\mathrm{I}}-\mathbf{H}$ and formic acid production.

In addition, these electrocatalytic tests in presence of various CPET mediators highlight several key features regarding the role of these mediators on the catalytic activity of $\mathbf{M n}^{\mathrm{I}}$-cat. First, a substantial enhancement of $\mathrm{CO}_{2} \mathrm{RR}$ activity of $\mathbf{M n}{ }^{\mathrm{I}}$-cat was observed also in presence of CPET mediators such as $\mathbf{H}_{\mathbf{2}} \mathbf{Q}$ without change of selectivity (Fig2B and Fig 4A), promoting the selective $\mathrm{CO}_{2} \mathrm{RR}$ to $\mathrm{CO}$. We assigned this strong rate enhancement to the fact that the BDFE value of $\mathbf{H}_{2} \mathbf{Q}$ is too high to enable the generation of $\mathbf{M n} \mathbf{I}-\mathbf{H}$ species, but that $\mathbf{H}_{2} \mathbf{Q}$ still acts as a CPET mediator to enhance the rate of $\mathrm{CO}_{2}$ reduction, promoting faster proton-electron transfer to the activated $\mathrm{CO}_{2}$ molecule in the known $\mathrm{CO}_{2}$ to $\mathrm{CO}$ reaction pathway using $\mathbf{M n}^{\mathbf{I}}$-cat.(38) Such rate enhancement without a change in selectivity has recently been reported for $\mathrm{CO}_{2} \mathrm{RR}$ to $\mathrm{CO}$ using iron porphyrin complexes in combination with a synthetic NADH analogue as CPET mediator.(39) Second, the $\mathrm{CO}_{2} \mathrm{RR}$ catalytic performances for $\mathrm{HCOOH}$ obtained using $\mathbf{F e}-\mathbf{S}$ as mediator $\left(\mathrm{TON}_{\mathrm{HCOOH}}=\sim 4\right)$ are significantly better than using Ru-NH $\left(\mathrm{TON} \mathrm{NCOOH}_{\mathrm{H}}=\sim 0.8\right)$ and $\mathbf{D} \mathbf{T H}_{2} \mathbf{Q}\left(\mathrm{TON}_{\mathrm{HCOOH}}=\sim 0.9\right)$ (Table S1). .

The small difference in BDFE values of the above mentioned CPET mediators (below $1 \mathrm{kcal} / \mathrm{mol}$ between $\mathbf{R u}-\mathbf{N H}, \mathbf{D T H}_{\mathbf{2}} \mathbf{Q}$ and $\mathbf{F e}-\mathbf{S}$ ) appears unlikely to explain this strong discrepancy in $\mathrm{CO}_{2} \mathrm{RR}$ TONs for $\mathrm{HCOOH}$. We hypothesized that the lower observed TONs resulted from the two points identified above as critical for an efficient regeneration of the CPET mediators, namely the ability of the proton source to transfer a proton to the mediator and the fast reduction of the oxidized mediator. Ru-NH here fails at meeting the first point, as the low $\mathrm{p} K_{\mathrm{a}}$ of Ru-NH ( $\left.K_{\mathrm{a}}=22\right)$ significantly hinders the protonation of the corresponding base $\left(\mathbf{R u}-\mathbf{N}^{-}\right)$in the presence of TFE under a $\mathrm{CO}_{2}$ atmosphere $\left(\mathrm{p} K_{\mathrm{a}}=25.1\right)$. To confirm this hypothesis, we carried out an analogous CPE experiment using Ru-NH as a mediator but in presence of $1.5 \mathrm{M} \mathrm{H}_{2} \mathrm{O}$ instead of TFE. In such conditions, the in situ generated $\mathrm{H}_{2} \mathrm{CO}_{3}\left(\mathrm{p} K_{\mathrm{a}}=17\right.$ in $\left.\mathrm{CH}_{3} \mathrm{CN}\right)$ should enable the protonation of the electrogenerated Ru-N' $\mathbf{N}^{-}$species. CPE data confirmed this hypothesis with an enhancement in TON (2.3) and FY for $\mathrm{HCOOH}$ production $(60 \%)$. However, the presence of $\mathrm{H}_{2}$ suggests that protonation of the Mn hydride species occurs in presence of stronger acid and further illustrates the importance of avoiding the use of proton sources with lower $\mathrm{p} K$ a values. Similarly, we hypothesize the $\mathrm{p} K_{\mathrm{a}}$ value of $\mathbf{D} \mathbf{T H}_{\mathbf{2}} \mathbf{Q}$ is too low to enable its regeneration in the reaction conditions even using $\mathrm{H}_{2} \mathrm{O}$ instead of TFE (see section 7 of Supplementary Materials). To mitigate that point, we carried out a CPE in presence of a large excess of $\mathbf{D T H}_{2} \mathbf{Q}(0.11 \mathrm{M})$ and no TFE, and observed substantially higher FY for $\mathrm{HCOOH}(65 \%)$ and a lower amount of $\mathrm{CO}(\mathrm{FY}=28 \%)$, highlighting the ability of $\mathbf{D T H}_{2} \mathbf{Q}$ to quantitively generate $\mathbf{M n}{ }^{\mathbf{I}}-\mathbf{H}$.

Nevertheless, the reaction rates remained slow and the TON moderate (Fig. S16 and Table S5). We conjectured that the lower performance of $\mathbf{D T H} \mathbf{T H}_{2} \mathbf{Q}$ results from kinetic limitations arising from its high steric bulk, that in a Marcus normal region can be translated into an increased donor-acceptor distance lowering both rates for CPET transfer and regeneration at the electrode.

These results further highlight that Fe-S is a remarkably effective CPET mediator for the current catalytic system, as it perfectly fulfills the boundary conditions described in Fig. 3A: 
it possesses a low $\mathrm{BDFE}^{[\mathrm{Fe}-\mathrm{S}] \mathrm{H}}$, verifies the $\mathrm{BDFE}^{[\mathrm{Fe}-\mathrm{S}] \mathrm{H}}<\mathrm{BDFE}^{\mathrm{Mn}-\mathrm{H}}$ relationship and can be efficiently regenerated by protonation of the reduced $\mathbf{F e - S}-\mathbf{S}^{-}$species with TFE, as its $\mathrm{p} K_{\mathrm{a}}$ value is significantly higher than the $\mathrm{p} K_{\mathrm{a}}$ value of TFE under a $\mathrm{CO}_{2}$ atmosphere (25.1). In addition, the close BDFE values of [Fe-S] $\mathbf{H}$ and $\mathbf{M} \mathbf{n}^{\mathrm{I}}-\mathbf{H}$ and the intrinsic low reorganization energy of Fe-S allow maximizing the efficiency of the (re)generation of the CPET mediator. Relatedly, this efficient regeneration in presence of mild proton sources prevents the direct protonation of the Mn hydride species generated upon CPET and ensures a high selectivity towards undesired $\mathrm{H}_{2}$ evolution.

These results serve as a proof of concept for the rational choice of a CPET mediator enabling catalytic metal hydride formation and showcase the potential of synthetic Fe-S clusters as CPET mediators owing to their low reorganization energy, the simple tuning of their redox potential upon modulation of their ligand framework. A wide number of catalytic reactions for which metal hydrides have been identified as key intermediates could benefit from the approach and guiding principle presented in this work.

\section{References and Notes}

1. R. M. Bullock, M. L. Helm, Molecular Electrocatalysts for Oxidation of Hydrogen Using Earth-Abundant Metals: Shoving Protons Around with Proton Relays. Acc. Chem. Res. 48, 2017-2026 (2015).

2. R. Francke, B. Schille, M. Roemelt, Homogeneously Catalyzed Electroreduction of Carbon Dioxide-Methods, Mechanisms, and Catalysts. Chem. Rev. 118, 4631-4701 (2018).

3. D. Wang, D. Astruc, The Golden Age of Transfer Hydrogenation. Chem. Rev. 115, 6621-6686 (2015).

4. C. Gunanathan, D. Milstein, Applications of Acceptorless Dehydrogenation and Related Transformations in Chemical Synthesis. Science 341, 1229712 (2013).

5. N. Elgrishi, D. A. Kurtz, J. L. Dempsey, Reaction Parameters Influencing Cobalt Hydride Formation Kinetics: Implications for Benchmarking $\mathrm{H}_{2}$-Evolution Catalysts. J. Am. Chem. Soc. 139, 239-244 (2017).

6. T. Huang, E. S. Rountree, A. P. Traywick, M. Bayoumi, J. L. Dempsey, Switching between Stepwise and Concerted Proton-Coupled Electron Transfer Pathways in Tungsten Hydride Activation. J. Am. Chem. Soc. 140, 14655-14669 (2018).

7. H. Noh et al., Redox-Mediator-Assisted Electrocatalytic Hydrogen Evolution from Water by a Molybdenum Sulfide-Functionalized Metal-Organic Framework. ACS Catal. 8, 9848-9858 (2018).

8. B. Rausch, M. D. Symes, L. Cronin, A Bio-Inspired, Small Molecule ElectronCoupled-Proton Buffer for Decoupling the Half-Reactions of Electrolytic Water Splitting. J. Am. Chem. Soc. 135, 13656-13659 (2013).

9. A. Dutta, A. M. Appel, W. J. Shaw, Designing electrochemically reversible $\mathrm{H}_{2}$ oxidation and production catalysts. Nat. Rev. Chem. 2, 244-252 (2018).

10. N. E. Smith, W. H. Bernskoetter, N. Hazari, The Role of Proton Shuttles in the Reversible Activation of Hydrogen via Metal-Ligand Cooperation. J. Am. Chem. Soc. 141, 17350-17360 (2019).

11. A. Badalyan, S. S. Stahl, Cooperative electrocatalytic alcohol oxidation with electronproton-transfer mediators. Nature 535, 406-410 (2016).

12. E. A. McLoughlin, K. C. Armstrong, R. M. Waymouth, Electrochemically Regenerable Hydrogen Atom Acceptors: Mediators in Electrocatalytic Alcohol Oxidation Reactions. ACS Catal. 10, 11654-11662 (2020). 
13. C. M. Galvin, R. M. Waymouth, Electron-Rich Phenoxyl Mediators Improve Thermodynamic Performance of Electrocatalytic Alcohol Oxidation with an Iridium Pincer Complex. J. Am. Chem. Soc. 142, 19368-19378 (2020).

14. M. J. Chalkley, P. Garrido-Barros, J. C. Peters, A molecular mediator for reductive concerted proton-electron transfers via electrocatalysis. Science 369, 850 (2020).

15. C. W. Anson, S. S. Stahl, Cooperative Electrocatalytic $\mathrm{O}_{2}$ Reduction Involving Co(salophen) with p-Hydroquinone as an Electron-Proton Transfer Mediator. J. Am. Chem. Soc. 139, 18472-18475 (2017).

16. M. Bourrez, F. Molton, S. Chardon-Noblat, A. Deronzier, $\left[\mathrm{Mn}(\right.$ bipyridyl $\left.)(\mathrm{CO})_{3} \mathrm{Br}\right]$ : an abundant metal carbonyl complex as efficient electrocatalyst for $\mathrm{CO}_{2}$ reduction. Angew. Chem. Int. Ed. 50, 9903-9906 (2011).

17. H. Takeda, H. Koizumi, K. Okamoto, O. Ishitani, Photocatalytic $\mathrm{CO}_{2}$ reduction using a Mn complex as a catalyst. Chem. Commun. 50, 1491-1493 (2014).

18. X. Wang et al., Site-isolated manganese carbonyl on bipyridine-functionalities of periodic mesoporous organosilicas: efficient $\mathrm{CO}_{2}$ photoreduction and detection of key reaction intermediates. Chem. Sci. 8, 8204-8213 (2017).

19. M. H. Rønne et al., Ligand-Controlled Product Selectivity in Electrochemical Carbon Dioxide Reduction Using Manganese Bipyridine Catalysts. J. Am. Chem. Soc. 142, 4265-4275 (2020).

20. M. Bhattacharya, S. Sebghati, R. T. VanderLinden, C. T. Saouma, Toward Combined Carbon Capture and Recycling: Addition of an Amine Alters Product Selectivity from $\mathrm{CO}$ to Formic Acid in Manganese Catalyzed Reduction of $\mathrm{CO}_{2}$. J. Am. Chem. Soc. 142, 17589-17597 (2020).

21. C. T. Saouma, W. D. Morris, J. W. Darcy, J. M. Mayer, Protonation and ProtonCoupled Electron Transfer at S-Ligated [4Fe-4S] Clusters. Chem. Eur. J. 21, 9256-9260 (2015).

22. M. Tilset, V. D. Parker, Solution homolytic bond dissociation energies of organotransition-metal hydrides. J. Am. Chem. Soc. 111, 6711-6717 (1989).

23. M. Senger et al., Proton-Coupled Reduction of the Catalytic [4Fe-4S] Cluster in [FeFe]Hydrogenases. Angew. Chem. Int. Ed. 56, 16503-16506 (2017).

24. R. Camba et al., Mechanisms of Redox-Coupled Proton Transfer in Proteins: Role of the Proximal Proline in Reactions of the [3Fe-4S] Cluster in Azotobacter vinelandii Ferredoxin I. Biochemistry 42, 10589-10599 (2003).

25. A. Albers et al., Fast Proton-Coupled Electron Transfer Observed for a High-Fidelity Structural and Functional [2Fe-2S] Rieske Model. J. Am. Chem. Soc. 136, 3946-3954 (2014).

26. P. Kennepohl, E. I. Solomon, Electronic Structure Contributions to Electron-Transfer Reactivity in Iron-Sulfur Active Sites: 3. Kinetics of Electron Transfer. Inorg. Chem. 42, 696-708 (2003).

27. E. Sigfridsson, M. H. M. Olsson, U. Ryde, Inner-Sphere Reorganization Energy of Iron-Sulfur Clusters Studied with Theoretical Methods. Inorg. Chem. 40, 2509-2519 (2001).

28. F. Franco et al., Local Proton Source in Electrocatalytic $\mathrm{CO}_{2}$ Reduction with [Mn(bpy$\mathrm{R})(\mathrm{CO})_{3} \mathrm{Br}$ ] Complexes. Chem. Eur. J. 23, 4782-4793 (2017).

29. F. A. Cotton, J. L. Down, G. Wilkinson, 167. Infrared spectra of manganese carbonyl hydride and deuteride. J. Chem. Soc., 833-837 (1959).

30. C. W. Machan, M. D. Sampson, S. A. Chabolla, T. Dang, C. P. Kubiak, Developing a Mechanistic Understanding of Molecular Electrocatalysts for $\mathrm{CO}_{2}$ Reduction using Infrared Spectroelectrochemistry. Organometallics 33, 4550-4559 (2014).

31. S. Hammes-Schiffer, Theoretical Perspectives on Proton-Coupled Electron Transfer Reactions. Acc. Chem. Res. 34, 273-281 (2001). 
32. J. M. Mayer, Understanding Hydrogen Atom Transfer: From Bond Strengths to Marcus Theory. Acc. Chem. Res. 44, 36-46 (2011).

33. K. M. Waldie, A. L. Ostericher, M. H. Reineke, A. F. Sasayama, C. P. Kubiak, Hydricity of Transition-Metal Hydrides: Thermodynamic Considerations for $\mathrm{CO}_{2}$ Reduction. ACS Catal. 8, 1313-1324 (2018).

34. B. M. Ceballos, J. Y. Yang, Directing the reactivity of metal hydrides for selective $\mathrm{CO}_{2}$ reduction. Proc. Nat. Acad. Sci. 115, 12686 (2018).

35. T. H. Parsell, M.-Y. Yang, A. S. Borovik, C-H Bond Cleavage with Reductants: ReInvestigating the Reactivity of Monomeric $\mathrm{Mn}^{\mathrm{III} / \mathrm{IV}}-\mathrm{Oxo}$ Complexes and the Role of Oxo Ligand Basicity. J. Am. Chem. Soc. 131, 2762-2763 (2009).

36. S. Pattanayak et al., Spectroscopic and Reactivity Comparisons of a Pair of bTAML Complexes with $\mathrm{Fe}^{\mathrm{V}}=\mathrm{O}$ and $\mathrm{Fe}^{\mathrm{IV}}=\mathrm{O}$ Units. Inorg. Chem. 56, 6352-6361 (2017).

37. G. Qiu, R. R. Knowles, Rate-Driving Force Relationships in the Multisite ProtonCoupled Electron Transfer Activation of Ketones. J. Am. Chem. Soc. 141, 2721-2730 (2019).

38. C. Riplinger, M. D. Sampson, A. M. Ritzmann, C. P. Kubiak, E. A. Carter, Mechanistic Contrasts between Manganese and Rhenium Bipyridine Electrocatalysts for the Reduction of Carbon Dioxide. J. Am. Chem. Soc. 136, 16285-16298 (2014).

39. P. T. Smith, S. Weng, C. J. Chang, An NADH-Inspired Redox Mediator Strategy to Promote Second-Sphere Electron and Proton Transfer for Cooperative Electrochemical $\mathrm{CO}_{2}$ Reduction Catalyzed by Iron Porphyrin. Inorg. Chem. 59, 9270-9278 (2020).

Acknowledgments: We thank Liam Grunwald and Ahmed Mouchfiq for technical assistance and preliminary studies and Dr René Verel for assistance with NMR studies.

\section{Funding:}

Agence Nationale pour la Recherche, ANR Jeune Chercheur-Jeune Chercheuse ANR17-CE05-0021 (SD, VM)

European Research Council (ERC) under the European Union's Horizon 2020 research and innovation programme (grant agreement No. [853064]) (SD, FM, VM)

Swiss National Science Foundation (SNSF) project funding (grant No 200021_197153 / 1 (VM))

\section{Author contributions:}

Conceptualization: SD, VM

Methodology: SD, VM

Investigation: SD, FM, EB

Funding acquisition: VM

Project administration: MF, VM

Supervision: VM

Writing - original draft: SD, FM, VM

Writing - review \& editing: SD, FM, MF, VM

Competing interests: Authors declare that they have no competing interests.

Data and materials availability: All data are available in the main text or the supplementary materials. 